\title{
Manometric pattern progression in esophageal achalasia in the era of high-resolution manometry
}

\author{
Renato Salvador ${ }^{1}$, Mario Costantini ${ }^{1}$, Salvatore Tolone ${ }^{2}$, Pietro Familiari ${ }^{3}$, Ermenegildo Galliani ${ }^{4}$, \\ Bastianello Germanà ${ }^{4}$, Edoardo Savarino ${ }^{1}$, Stefano Merigliano ${ }^{1}$, Michele Valmasoni ${ }^{1}$ \\ ${ }^{1}$ Department of Surgery, Oncology and Gastroenterology, School of Medicine, University of Padova, Padova, Italy; ${ }^{2}$ Division of General, Mininvasive \\ and Bariatric Surgery, University of Campania "Luigi Vanvitelli", Naples, Italy; ${ }^{3}$ Digestive Endoscopy Unit, Catholic University of Sacred Heart, \\ Rome, Italy; ${ }^{4}$ Gastroenterology Unit, San Martino Hospital, ULSS 1, Belluno, Italy \\ Contributions: (I) Conception and design: R Salvador, M Costantini, E Savarino, S Tolone, M Valmasoni; (II) Administrative support: R Salvador, S \\ Merigliano, B Germanà, S Tolone, E Savarino, P Familiari; (III) Provision of study materials or patients: R Salvador, M Costantini, E Savarino, E \\ Galliani, S Tolone, P Familiari, B Germanà, S Merigliano; (IV) Collection and assembly of data: R Salvador, M Costantini, E Savarino, S Tolone, P \\ Familiari, E Galliani; (V) Data analysis and interpretation: All authors; (VI) Manuscript writing: All authors; (VII) Final approval of manuscript: All \\ authors. \\ Correspondence to: Renato Salvador, MD. Department of Surgery, Oncology and Gastroenterology, University of Padova, Clinica Chirurgica 3, \\ Policlinico Universitario, Padova, Italy. Email: renato.salvador@unipd.it.
}

\begin{abstract}
Esophageal manometry represents the gold standard technique for the diagnosis of esophageal achalasia because it can detect both the lack of lower esophageal sphincter (LES) relaxation and abnormal peristalsis. From the manometric standpoint, cases of achalasia can be segregated on the grounds of three clinically relevant patterns according to the Chicago Classification v3.0. It is currently unclear whether they represent distinct entities or are part of a disease continuum with the possibility of transition from a pattern to another one. The four cases described in the present report could provide further insights on this topic because the manometric pattern changed from type III to type II in all patients-without any invasive treatment. The cases described here support the hypothesis that the different manometric patterns of achalasia represent different stages in the evolution of the same disease, type III being the early stage, type II an intermediate stage, and type I probably the end stage of achalasia.
\end{abstract}

Keywords: Achalasia; manometric pattern; Padova theory

Submitted Dec 09, 2019. Accepted for publication Mar 12, 2020.

doi: $10.21037 /$ atm.2020.03.149

View this article at: http://dx.doi.org/10.21037/atm.2020.03.149

\section{Background}

Achalasia is an esophageal motility disorder characterized by an impaired lower esophageal sphincter (LES) relaxation and the absence of esophageal peristalsis, resulting in a functional outflow obstruction at the gastroesophageal junction $(1,2)$. This rare disease has an incidence of 1.6 cases per 100,000 population a year $(3,4)$.

Esophageal achalasia can be classified according to manometric characteristic and/or radiological findings (Figures 1,2) $(5,6)$.
From the manometric standpoint, cases of esophageal achalasia are distinguished on the grounds of three clinically relevant patterns according to the Chicago Classification (5). It is currently unclear whether they represent distinct entities or are part of a disease continuum with the possibility of transition from one pattern to another.

Recently we proposed the hypothesis that the three patterns might represent three different stages of the same disease (7). Here we report on four cases of patients with esophageal achalasia who moved from a pattern into another without any treatment, thus supporting this hypothesis. 
Disorders with EGJ
outflow obstruction

Major disorders of peristalsis

Minor disorders of peristalsis

Normal

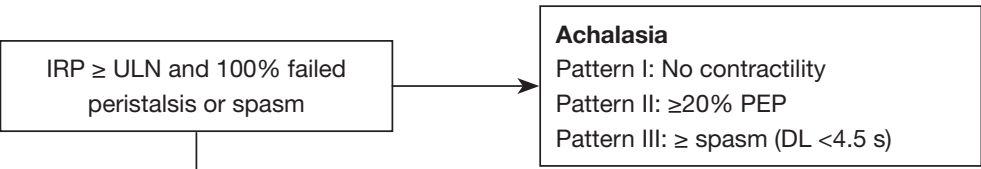

EGJ outflow obstruction

Incompletely expressed achalasia

Mechanical obstruction

DES:

- $\geq 20 \%$ premature ( $\mathrm{DL}<4.5 \mathrm{~s}$ )

Jackhammer esophagus:

- $\geq 20 \% \mathrm{DCl}>8.000 \mathrm{mmHg}^{*} \mathrm{~s}^{*} \mathrm{~cm}$

Absent contractility:

- No scorable contraction

- Consider achalasia

Ineffective motility (IEM):

- $\geq 50 \%$ ineffective swallows

Fragmented peristalsis:

- $\geq 50 \%$ fragmented swallows and not ineffective

Figure 1 The Classification of esophageal motility disorders. IRP, integrated relaxation pressure; ULN, upper limit of normal; PEP, panesophageal pressurization; DL, distal latency; EGJ, esophageal-gastric-junction; DES, diffuse esophageal spasm; DCI, distal contractile integral.

\begin{tabular}{|l|c|c|}
\hline Radiological stage & Esophageal diameter $(\mathrm{cm})$ & Esophageal shape \\
\hline I & $<4$ & - \\
\hline II & $4-6$ & - \\
\hline III & $\geq 6$ & - \\
\hline IV & $\geq 6$ & Sigmoid-shaped \\
\hline
\end{tabular}

Figure 2 The radiological classification of esophageal achalasia.

\section{Case \#1}

A 76-year-old female outpatient was assessed for dysphagia, food regurgitation and chest pain elsewhere 3 years ago. Endoscopy suggested gastroesophageal reflux disease (GERD) due to a hypotonic cardia, although the absence of esophageal mucosal injuries or hiatal hernia. Highresolution manometry (HRM) of the esophagus revealed achalasia type III (with 4 premature contractions), however, with a median esophageal-gastric-junction (EGJ) basal pressure of $40.2 \mathrm{mmHg}$, and an integrated relaxation pressure (IRP) of $25 \mathrm{mmHg}$. Barium swallow showed an undilated esophagus with tertiary waves and slow transit of the barium through the cardia.

The patient refused any treatment at the time because her symptoms were mild and intermittent.

In 2018, she was re-admitted to our esophageal clinic complaining of progressive dysphagia and reported a weight loss of $5 \mathrm{~kg}$ within the last 6 months. A follow-up barium swallow showed a moderately dilated esophagus, while endoscopy revealed no difference compared with the procedure performed 3 years before. Esophageal HRM manometry was repeated, revealing a pattern II achalasia with an EGJ basal pressure of $52.7 \mathrm{mmHg}$, and an IRP of $33.8 \mathrm{mmHg}$. 

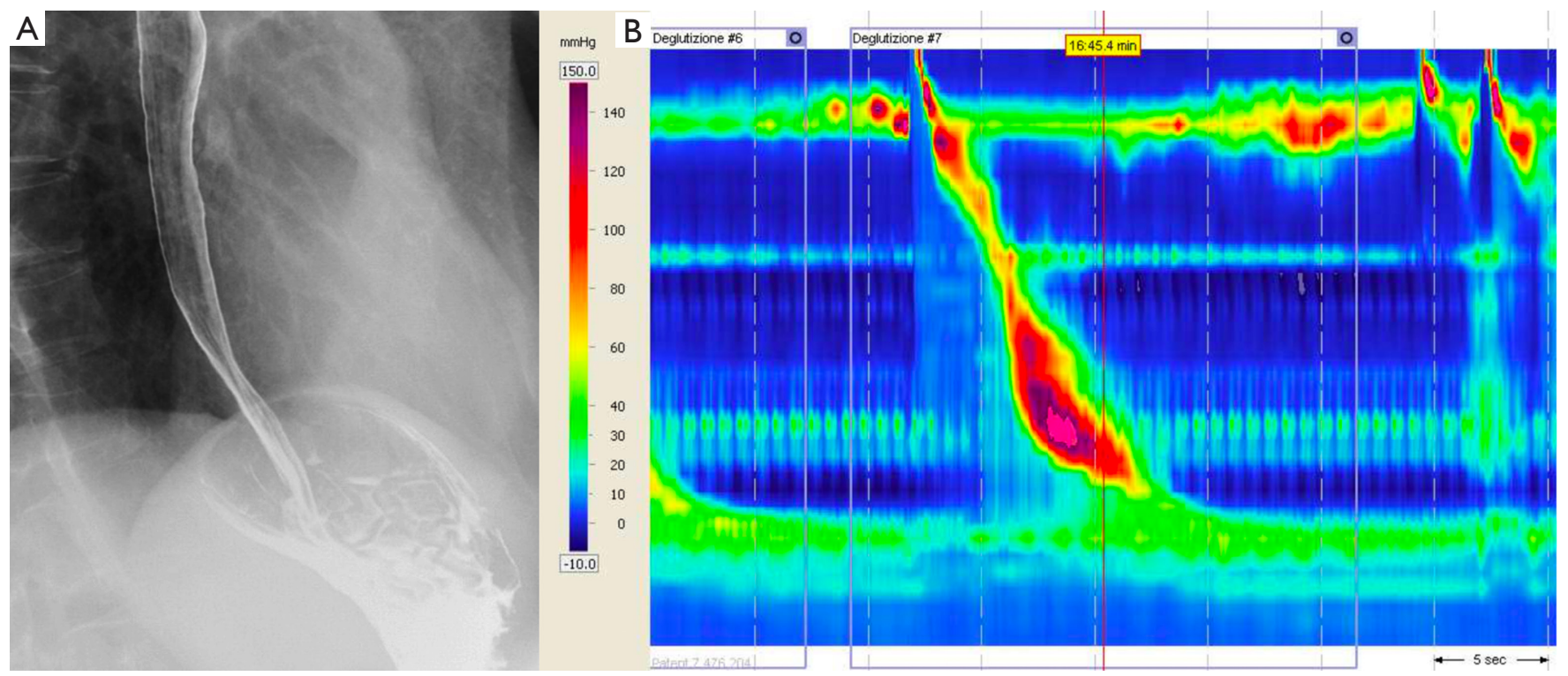

Figure 3 Case\#2. (A) First barium swallow showing no dilation of the esophagus and a normal transit through the cardia; (B) the HRM study showed an Outflow obstruction with normal peristalsis. HRM, high-resolution manometry.

The patient underwent laparoscopic Heller myotomy with a Dor fundoplication and is currently symptom-free, 3 months after her surgical procedure.

\section{Case \#2}

A 76-year-old female underwent manometry and $\mathrm{pH}$ monitoring for symptoms typical of gastric reflux (heartburn and regurgitation) 3 years ago. A few months before coming to our attention, an endoscopy had been suggestive of a hypotensive LES. On HRM, her EGJ showed a normal basal pressure with a median IRP $15.3 \mathrm{mmHg}$ (n.v. $<15 \mathrm{mmHg}$ ). The motility of the esophageal body was normal. The picture emerging from $\mathrm{pH}$ monitoring was normal. Barium swallow showed an undilated esophagus with a normal transit through the cardia (Figure 3).

Eighteen months later, esophageal HRM was repeated because the patient started to complain of dysphagia and food regurgitation. Once again, the EGJ basal pressure, and relaxation were both normal. The esophageal body showed a $100 \%$ simultaneous contraction with 3 spastic waves, however, so achalasia type III was considered in spite of the normal IRP (Chicago Classification v3.0 and Salvador et al.) $(5,7,8)$. We lost track of the patient for a year, then she returned to our laboratory for repeat manometry due to a worsening dysphagia. The new HRM revealed a typical type II achalasia, with a LES basal pressure of $45.3 \mathrm{mmHg}$ and a severely impaired EGJ relaxation (IRP was $29.8 \mathrm{mmHg}$ ). Barium swallow showed a slow transit to the cardia ("bird's beak" sign) with stasis in the distal part of the esophagus (Figure 4). The patient underwent laparoscopic Heller myotomy with a Dor fundoplication with complete symptoms resolution, also at 12 months after surgery.

\section{Case \#3}

A 63-year-old male complained intermittent non-cardiac chest pain in the last 5 years. One year ago, he developed also paradoxical dysphagia with mild regurgitation; he immediately underwent upper endoscopy that was negative and then to HRM. At this latter, EGJ showed a basal pressure of $42 \mathrm{mmHg}$ but with an impaired post-deglutitive relaxation (median IRP $17.6 \mathrm{mmHg}^{*} \mathrm{~s}$ ). The motility of the esophageal body was aperistaltic, with a combination of panpressurization and premature and spastic contractions (60\% and $40 \%$, respectively). The final report of the procedure was pattern III Achalasia.

Patient was informed of his pathology and a surgical procedure was proposed elsewhere. He preferred to ask for a second opinion because of the intermitting features of his symptoms. 

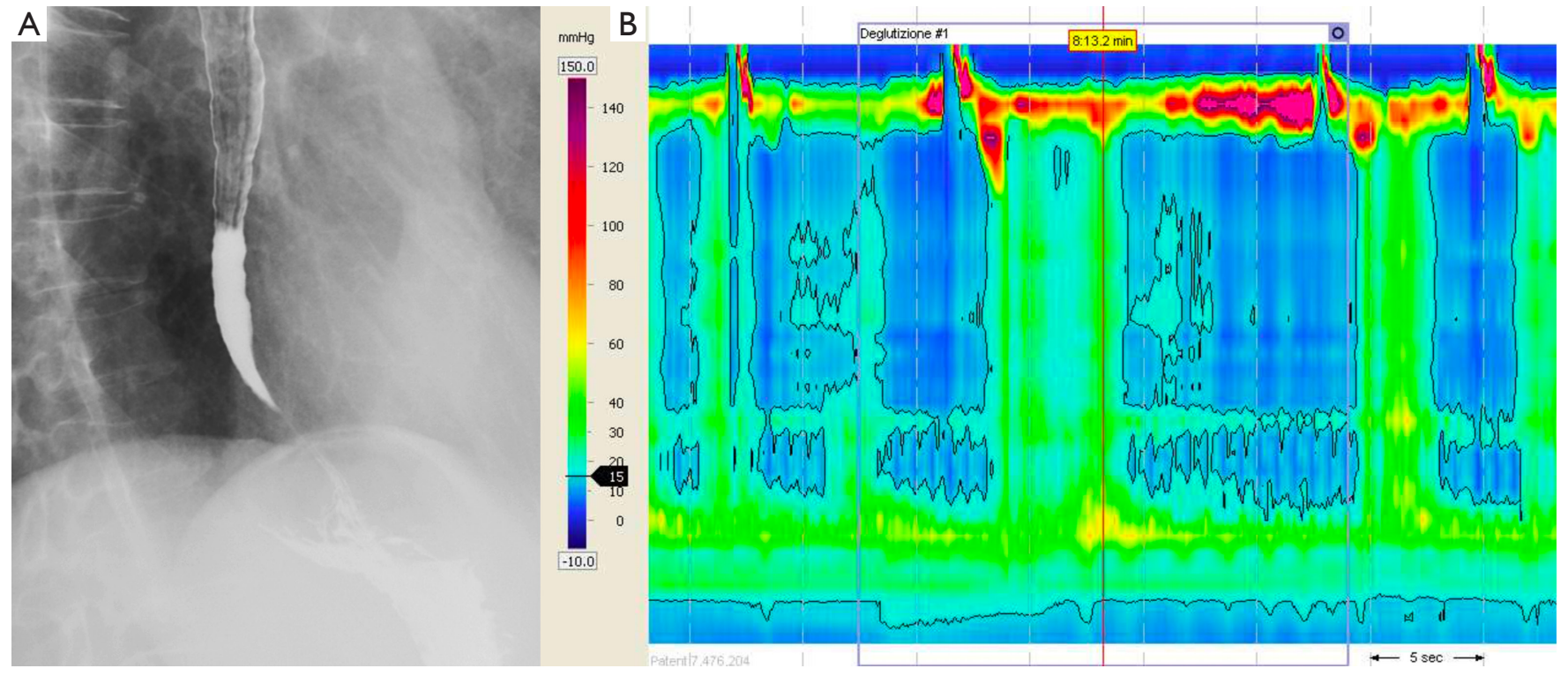

Figure 4 Case \#2. (A) Second barium swallow (3 years later) showing a slow transit of the barium to the cardia ("bird beak" sign); (B) the HRM picture reveled a pattern II achalasia. HRM, high-resolution manometry.

After 6 months we decided to repeat an upper endoscopy, a barium swallow and HRM. At upper endoscopy a mild pop-opening at EGJ was noticed, with a small paraesophageal hernia; biopsy samples were negative for eosinophilic esophagitis. Barium swallow documented only mild spastic activity of the proximal esophageal body. HRM documented type II Achalasia pattern with $100 \%$ of panpressurization, EGJ resting pressure $46 \mathrm{mmHg}$ and median IRP $23 \mathrm{mmHg}^{*}$.

The patient underwent Laparoscopic Heller-Dor with hernia repair with complete symptoms resolution at 3 months follow-up.

\section{Case \#4}

A 46-year-old female complaining of chest pain underwent HRM 3 years ago. At HRM, EGJ had a normal basal pressure $(39.8 \mathrm{mmHg})$ with an impaired relaxation: median IRP $31.2 \mathrm{mmHg}$. The motility of the esophageal body was abnormal, with three premature and spastic contractions. According to Chicago Classification v3.0, the final report of the procedure was pattern III Achalasia (Figure 5).

Barium swallow showed an achalasia with radiological grade I.

Following the manometric pattern we proposed a Laparoscopic Heller-Dor since previous studies demonstrated that endoscopic treatments (i.e., pneumatic dilation and the Botox injection) showed a lesser outcome compared to surgery in this particular group of patients (9).

However, the patient decided to wait because her symptoms did not impact on her quality of life.

Three year later, HRM and barium swallow was repeated for worsening dysphagia and food regurgitation. The manometry revealed a typical type II achalasia, with an EGJ basal pressure of $50.2 \mathrm{mmHg}$ and the IRP was $34.7 \mathrm{mmHg}$. The premature and spastic contractions were not evident anymore (Figure 6).

The patient underwent Laparoscopic Heller-Dor with complete symptoms relief (i.e., no dysphagia, food regurgitation and chest pain) at 6-month follow-up.

\section{Discussion}

With the introduction of HRM in clinical practice, we can now see motility disorders from another view. The advantages of HRM over conventional methods include a better identification of motility disorders, and this also gives us a chance to shed light on how they evolve. The development of a practical manometric device with 36 solid-state, circumferential sensors placed $1 \mathrm{~cm}$ apart enables the visualization of esophageal motility as a continuum along the length of the esophagus (10). This gives us a clear, graphic picture of any segmental and global abnormal motility and/or outflow obstruction, often enabling the 

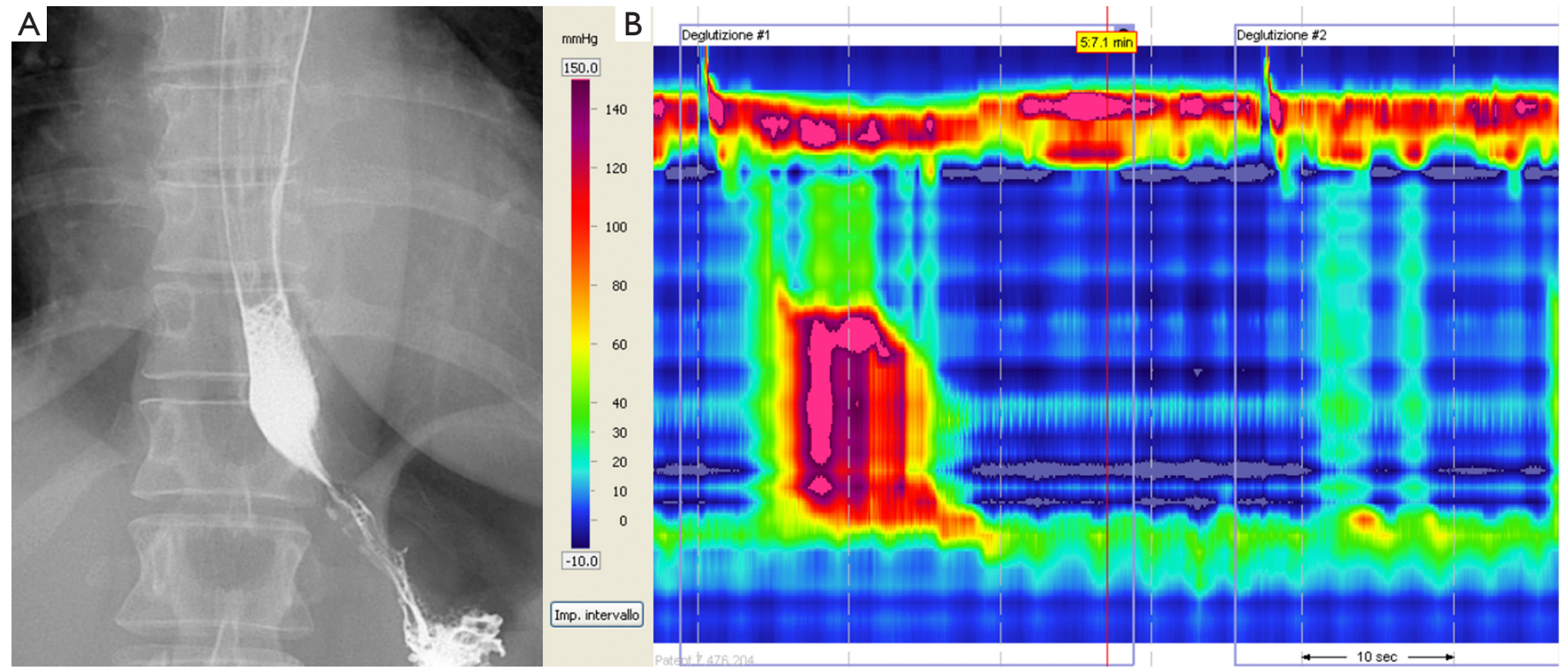

Figure 5 Case \#4. (A) First barium swallow showing a slow transit to the cardia with a radiological grade I achalasia; (B) the HRM showed a pattern III achalasia. HRM, high-resolution manometry.
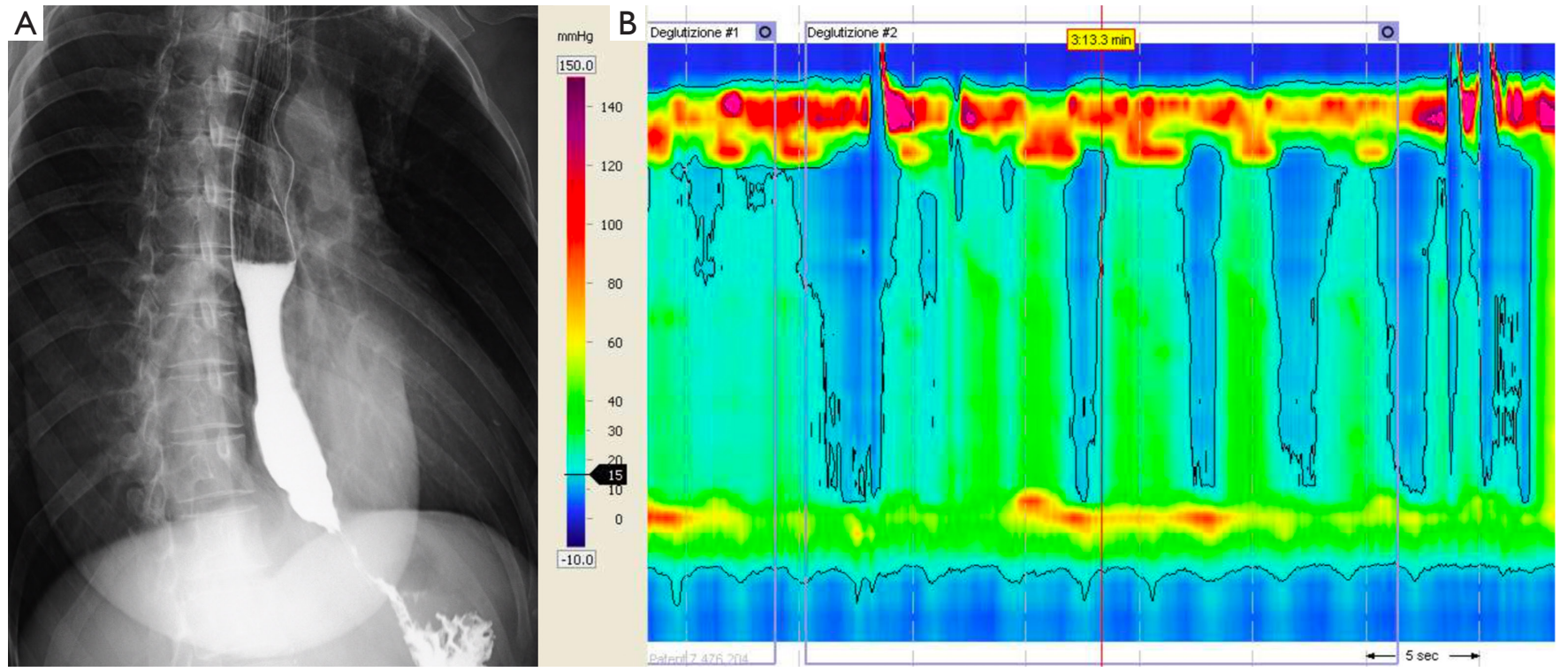

Figure 6 Case \#4. (A) Second barium swallow (3 years later) showing a radiological grade II achalasia; (B) HRM: pattern II achalasia. HRM, high-resolution manometry.

identification of motility disorders limited to a portion of the esophageal body (which might be overlooked by pressure sensors placed further apart). In fact, recent case reports from two groups, expert in the use of HRM, described the evolution from diffuse esophageal spasm to achalasia type III $(11,12)$. The possibility of such a transition from one form of esophageal disorder to another (from diffuse esophageal spasm to achalasia) has been known for decades, even relying on traditional manometry, ever since the landmark paper by Vantrappen in 1979 (13). Transitions to achalasia have also been reported from nutcracker esophagus $(14,15)$, and from other, nonspecific 
motility disorders $(16,17)$.

We recently advanced the hypothesis that the three different manometric patterns seen in achalasia, and described by the Chicago Classification v3.0 (5), may represent different stages in the evolution of the disease $(7,18)$. The strongest finding to support the "Padova theory" concerned the very different, gradually-widening preoperative esophageal diameters, which became larger from achalasia type III to types II and I. In addition, all patients with a sigmoid-shaped mega-esophagus (radiological grade IV) had a manometric pattern corresponding to achalasia type I. Another two results reinforcing our hypothesis concerned the fact that type III patients tended to have a shorter history of symptoms than patients with types I or II (this would again correlate type III with an earlier-stage disease and a smaller esophageal diameter), and that patients with type I achalasia had a higher mean symptom score than patients with types II or III. On patient follow-up after surgery, none of those with types I or II preoperatively showed type III achalasia after treatment, whereas around $50 \%$ of the patients with preoperative type III changed to achalasia types I or II after the Heller-Dor procedure. The main weakness of the study findings lay in that the patients were treated surgically, and this may have influenced any changes seen in their postoperative manometric patterns (7).

The four cases described in the present report could overcome this weakness because the manometric pattern changed from type III to type II in all patients-without any invasive treatment. This changing manometric pattern was seen in three cases already diagnosed as achalasia. In one case, we saw a transition from a normal manometric picture to the pattern of achalasia type III, and then to achalasia type II. This "mutation" coincided with worsening of patients' symptoms.

\section{Conclusions}

The cases described here strongly support the hypothesis that the different manometric patterns of achalasia represent different stages in the evolution of the same disease, type III being the early stage, type II an intermediate stage, and type I the end stage of achalasia.

\section{Acknowledgments}

Funding: None.

\section{Footnote}

Conflicts of Interest: All authors have completed the ICMJE uniform disclosure form (available at http://dx.doi. org/10.21037/atm.2020.03.149). The authors have no conflicts of interest to declare.

Etbical Statement: The authors are accountable for all aspects of the work in ensuring that questions related to the accuracy or integrity of any part of the work are appropriately investigated and resolved.

Open Access Statement: This is an Open Access article distributed in accordance with the Creative Commons Attribution-NonCommercial-NoDerivs 4.0 International License (CC BY-NC-ND 4.0), which permits the noncommercial replication and distribution of the article with the strict proviso that no changes or edits are made and the original work is properly cited (including links to both the formal publication through the relevant DOI and the license). See: https://creativecommons.org/licenses/by-nc-nd/4.0/.

\section{References}

1. Pandolfino JE, Kwiatek MA, Nealis T, et al. Achalasia: a new clinically relevant classification by high-resolution manometry. Gastroenterology 2008;135:1526-33.

2. Williams VA, Peters JH. Achalasia of the esophagus: a surgical disease. J Am Coll Surg 2009;208:151-62.

3. Gennaro N, Portale G, Gallo C, et al. Esophageal achalasia in the Veneto region: epidemiology and treatment. Epidemiology and treatment of achalasia. J Gastrointest Surg 2011;15:423-8.

4. Park W, Vaezi MF. Etiology and pathogenesis of achalasia: the current understanding. Am J Gastroenterol 2005;100:1404-14.

5. Kahrilas PJ, Bredenoord AJ, Fox M, et al. The Chicago Classification of esophageal motility disorders, v3.0. Neurogastroenterol Motil 2015;27:160-74.

6. Henderson RD, Barichello AW, Pearson FG, et al. Diagnosis of achalasia. Can J Surg 1972;15:190-201.

7. Salvador R, Voltarel G, Savarino E, et al. The natural history of achalasia: Evidence of a continuum-"The evolutive pattern theory". Dig Liver Dis 2018;50:342-7.

8. Salvador R, Savarino E, Pesenti E, et al. The Impact of Heller Myotomy on Integrated Relaxation Pressure in Esophageal Achalasia. J Gastrointest Surg 2016;20:125-31; 
discussion 131.

9. Boeckxstaens G, Zaninotto G. Achalasia and esophagogastric junction outflow obstruction: focus on the subtypes. Neurogastroenterol Motil 2012;24 Suppl 1:27-31.

10. Kahrilas PJ, Ghosh SK, Pandolfino JE. Challenging the limits of esophageal manometry. Gastroenterology 2008;134:16-8.

11. Samo S, Carlson DA, Kahrilas PJ, et al. Ineffective Esophageal Motility Progressing into Distal Esophageal Spasm and Then Type III Achalasia. ACG Case Rep J 2016;3:e183.

12. De Schepper HU, Smout AJ, Bredenoord AJ. Distal esophageal spasm evolving to achalasia in high resolution. Clin Gastroenterol Hepatol 2014;12:A25-6.

13. Vantrappen G, Janssens J, Hellemans J, et al. Achalasia, diffuse esophageal spasm, and related motility disorders. Gastroenterology 1979;76:450-7.

Cite this article as: Salvador $\mathrm{R}$, Costantini M, Tolone S, Familiari P, Galliani E, Germanà B, Savarino E, Merigliano S, Valmasoni M. Manometric pattern progression in esophageal achalasia in the era of high-resolution manometry. Ann Transl Med 2021;9(10):906. doi: 10.21037/atm.2020.03.149
14. Paterson WG, Beck IT, Da Costa LR. Transition from nutcracker esophagus to achalasia. A case report. J Clin Gastroenterol 1991;13:554-8.

15. Anggiansah A, Bright NF, McCullagh M, et al. Transition from nutcracker esophagus to achalasia. Dig Dis Sci 1990;35:1162-6.

16. Shiflett DW, Wu WC, Ott DJ. Transition form nonspecific motility disorder to achalasia. Am J Gastroenterol 1980;73:325-8.

17. Naftali T, Levit T, Pomeranz I, et al. Nonspecific esophageal motility disorders may be an early stage of a specific disorder, particularly achalasia. Dis Esophagus 2009;22:611-5.

18. Salvador R, Savarino E, Pesenti E, et al. Effects of laparoscopic myotomy on the esophageal motility pattern of esophageal achalasia as measured by high-resolution manometry. Surg Endosc 2017;31:3510-8. 